\title{
Crop Classification by Polarimetric SAR
}

Skriver, Henning; Svendsen, Morten Thougaard; Nielsen, Flemming; Thomsen, Anton

Published in:

IEEE 1999 International Geoscience and Remote Sensing Symposium, 1999. IGARSS '99 Proceedings.

Link to article, DOI:

10.1109/IGARSS.1999.775119

Publication date:

1999

Document Version

Publisher's PDF, also known as Version of record

Link back to DTU Orbit

Citation (APA):

Skriver, H., Svendsen, M. T., Nielsen, F., \& Thomsen, A. (1999). Crop Classification by Polarimetric SAR. In IEEE 1999 International Geoscience and Remote Sensing Symposium, 1999. IGARSS '99 Proceedings. (pp. 2333-2335). IEEE. https://doi.org/10.1109/IGARSS.1999.775119

\section{General rights}

Copyright and moral rights for the publications made accessible in the public portal are retained by the authors and/or other copyright owners and it is a condition of accessing publications that users recognise and abide by the legal requirements associated with these rights.

- Users may download and print one copy of any publication from the public portal for the purpose of private study or research.

- You may not further distribute the material or use it for any profit-making activity or commercial gain

- You may freely distribute the URL identifying the publication in the public portal 


\title{
Crop Classification by Polarimetric SAR
}

\author{
Henning Skriver, Morten T. Svendsen', Flemming Nielsen ${ }^{2}$, and Anton Thomsen ${ }^{2}$ \\ ${ }^{1}$ Danish Center for Remote Sensing, Dept. Electromagnetic Systems \\ Technical University of Denmark, Building 348, DK-2800 Lyngby, Denmark \\ Phone: +45 458814 44, Fax: +45 459316 34, E-mail: hs@emi.dtu.dk \\ ${ }^{2}$ Danish Institute of Agricultural Sciences \\ Research Center Foulum, DK-8830 Tjele, Denmark
}

Polarimetric SAR-data of agricultural fields have been acquired by the Danish polarimetric L- and C-band SAR (EMISAR) during a number of missions at the Danish agricultural test site Foulum during 1995. The data are used to study the classification potential of polarimetric SAR data using the Wishart distributed covariance matrix. In general, the improvement of using polarimetric SAR data compared to multipolarization SAR data is larger at $L$-band compared to C-band. On the other hand, the variability due to natural variation and different incidence angles is larger at L-band compared to C-band.

\section{INTRODUCTION}

The potential of synthetic aperture radar (SAR) for agricultural applications has since long time been identified. The main advantage of the SAR is its all-weather mapping capabilities, which secures the mapping independent of cloud cover, that may prevent acquisition by optical and infrared sensors. Furthermore, the backscattering is sensitive to the dielectric properties of the vegetation and the soil, to the plant structure, to the surface roughness and to the canopy structure [1]. The extraction of agricultural parameters is based on and influenced by this sensitivity. It is well known, for instance, that the canopy development with time of different crops causes changes of the backscatter, and it is the basis for multi-temporal classification of ERS SAR data [2].

Studies for crop classification using polarimetric SAR data from the US AIRSAR have been performed for e.g. the Dutch Flevoland test site [3][4][5], and for the UK Feltwell test site [6]. Also, data from the SIR-C have been used for classification assessment [7]. These studies are based on single dates acquisitions, and study the use of linear polarizations and polarimetric parameters in conventional classification schemes [3][4][6], and in a neural network approach [6] with improved classification accuracies compared with the conventional methods. Also, classification methods based on the maximum polarimetric contrast procedure have been studied using the full polarimetric information [5][7]. The conclusion from these studies of single date, multifrequency ( $\mathrm{P}-, \mathrm{L}-$, and $\mathrm{C}$-band), polarimetric SAR data is that the polarimetric information is important.

In the present study the Danish airborne dual-frequency polarimetric SAR, EMISAR, has been-used [8]. Previously the classification potential has been assessed using the linear polarizations $\mathrm{HH}, \mathrm{VV}, \mathrm{HV}$ in various combinations, e.g. single polarization, multi-polarization, multi-frequency and multitemporal [9]. In this paper the analysis is extended to cover classification using the full polarimetric information. i.e. using the covariance matrix.

\section{DATA ACQUISITION}

The EMISAR has been developed at the Department of Electromagnetic Systems (EMI) of the Technical University of Denmark, and it is an L- and C-band fully polarimetric and interferometric SAR. The SAR system is installed on a Danish Air Force Gulfstream aircraft G-3. The SAR system is normally operated from an altitude of approximately $12.500 \mathrm{~m}$, the one-look spatial resolution is $2 \mathrm{~m}$ by $2 \mathrm{~m}$, and the ground range swath is approximately $12 \mathrm{~km}$. The processed data from this system are fully calibrated by using an internal calibration system.

A large number of acquisitions with both the C- and Lband polarimetric SAR has been carried out from 1994 to 1998 over a Danish agricultural test site. In 1995 data were acquired on March 22, May 1, June 8 and July 4 for L-band and on March 24, May 3 and July 4 for C-band. The L- and C-band acquisitions from May and from July have all been co-registered by identifying ground control points in the images. The resampling in connection with the coregistration has also been used to perform an averaging of the original one-look data to reduce the speckle by a cosinesquared weighted 9 by 9 filter. The new pixel spacing in the images is $5 \mathrm{~m}$ by $5 \mathrm{~m}$. From homogenous areas in the images the equivalent number of looks is estimated to approximately 8 and that corresponds to a standard deviation for the backscatter coefficient of approximately $1.5-2.0 \mathrm{~dB}$.

The test site contains a large number of agricultural fields with differentcrops and of differentsizes, as well as several lakes, forests, areas with natural vegetation and urban areas. The area is relatively flat, and corrections of the local incidence angle due to terrain slope are therefore not necessary. The crop types present in the area are spring barley, winter barley, winter wheat, rye, grass, winter rape, peas, potatoes, and beets, where spring barley, winter barley, winter wheat and winter rape are the most frequent crop types. A crop map was established for the test site including more than 200 fields covering different incidence angles. 
In May the spring crops are bare fields, and for the July acquisitions the beets are fully developed with broad leaves, for the peas the flowering is declining, the potato field consists of dense vegetation, and the spring barley is at the end of heading. For the winter crops the barley, wheat and rye are at the beginning of stem elongation, and the rape is at the beginning of heading in May. In July barley and rye are at the end of flowering, wheat is at the beginning of flowering and rape has finished the development of fruits.

\section{METHOD}

The polarimetric SAR measures the amplitude and phase of the backscattered signals in the four combinations of the linear receive and transmit polarizations hh, hv, vh and vv. These signals form the complex scattering matrix $\mathbf{S}$, where the elements $S_{p q}$ are the complex scattering amplitudes for receive polarization $p$ and transmit polarization $q$ ( $p$ and $q$ are either $v$ for vertical or $h$ for horizontal). In the case of reciprocity which normally applies for natural targets we have $S_{m}=S_{v h .}$ In the above-mentioned averaging the covariance matrix is formed for each averaged pixel:

$$
\langle\mathbf{C}\rangle=\left\{\begin{array}{lll}
\left\langle S_{h h} S_{h h}^{*}\right\rangle & \left\langle S_{h h} S_{h v}^{*}\right\rangle & \left\langle S_{h h} S_{v v}^{*}\right\rangle \\
\left\langle S_{h v} S_{h h}^{*}\right\rangle & \left\langle S_{h s_{h v}}\right\rangle & \left\langle S_{h v} S_{v v}^{*}\right\rangle \\
\left\langle S_{w} S_{h h}^{*}\right\rangle & \left\langle S_{w} S_{h v}^{*}\right\rangle & \left\langle S_{v v} S_{v v}^{*}\right\rangle
\end{array}\right\}
$$

where $\sigma$ denotes ensemble averaging, and * denotes complex conjugation.

The classification performed is based on the Bayes maximum likelihood classification scheme using the covariance matrix which is Wishart distributed [10]. Assuming that the data are statistically independent between the acquisitions, the generalized distance measure is [10]

$$
d\left(\mathbf{Z}, \omega_{m}\right)=\sum_{j=1}^{J} n\left\{\ln \left|\mathbf{C}_{m}(j)\right|+\operatorname{Tr}\left[\mathbf{C}_{m}(j)^{-1} \mathbf{Z}(j)\right]\right\}-\ln \left[P\left(\omega_{m}\right)\right]
$$

where $C_{m}(j)$ is the feature covariance matrix of the $m^{\text {th }}$ class in the $j^{\text {th }}$ acquisition, $\mathbf{Z}(j)$ is the covariance matrix of the $j^{\text {th }}$ acquisition for the pixel to be classified, $n$ is the number of looks, $\mathrm{P}\left(\omega_{\mathrm{m}}\right)$ is the a priori probability for class $\mathrm{m}, T r$ denotes the trace, and $\mathrm{J}$ is the total number of acquisitions.

One relatively large field (more than 500 pixels) has been picked for each of the above-mentioned crops. In addition, areas for forest, lake, and fallow fields have been selected. These areas have been used as training areas for the classifier, i.e. used to estimate the feature covariance matrix in (2). The pixels in the training areas have been classified and the classification accuracy estimated. This estimate is, of course, too optimistic. Therefore, a large number of test areas for the crops have been selected and the classification accuracy estimated for these areas, to test the sensitivity to for instance incidence angle and natural variability.

\section{RESULTS}

The classification accuracies are shown in Tables 1 and 2 for all the combinations of acquisitions. The classification accuracies for the individual crops are shown, as well as the total classification accuracy. For clarity the misclassifications are not shown in the tables. Table 1 shows the accuracy for the training areas and Table 2 shows the average accuracy for all test areas for each individual crop. The tables are divided into sections, i.e. section 1 is single frequency results for a single acquisition date, section 2 is dual-frequencyresults for a single acquisition date, section 3 is multitemporal results for a single frequency, and finally section 4 is combined multitemporal and dual-frequency results.

From the first section in Table 1 it is seen that the results for single acquisitions with a single frequency are not too bad with average classification accuracies from $61-73 \%$. The best performance is obtained by the L-band acquisitions, especially the acquisition in July with $73 \%$ classification accuracy. Compared with results using only the three linear polarizations in [9], the improvement of using the full polarimetric information is largest at L-band (about 15\%), whereas it is small at C-band. This is consistent with results in e.g. [11], where it is found that for instance the phase difference at $\mathrm{C}$-band is small for all crops. The results for the test areas in Table 2 show as expected a smaller classification accuracy than for the training areas. The decrease in accuracy for the single frequency, single acquisition date results are $22-26 \%$ for $\mathrm{L}$-band and C-band in May, whereas it is $11 \%$ for C-band in July. This is a result of the larger variability at $\mathrm{L}$-band compared to $\mathrm{C}$-band, and the larger variability in May compared to July [11]. In May for instance the surface scattering contribution to the total backscattering is large, and the dependence of the incidence angle is larger for surface scattering than for volume scattering. The large variability for the May acquisitions result in a large differencein the accuracy between training and test areas for spring barley, where the fields are bare fields. We observe that the winter barley is poorly classified especially for the May acquisitions, where it is confused primarily with winter wheat and rye.

In the second section of the two tables the results for dualfrequency, single acquisition date combinations show that the performance of the July acquisitions is better than the May acquisitions both for training and test areas, and we obtain an improvement in the classification accuracy for the training areas of $10-25 \%$ compared to the single frequency acquisitions. The multitemporal results in the third section of the tables show slightly better results than the dualfrequency combinations. The L-band multitemporal results are better for the training areas, whereas the opposite is the case for the test areas. Again, the reason is the larger difference for the polarimetric parameters between the individual crops at L-band, in addition to the larger variability at $L$-band. The dual-frequencyand multitemporal combination shows an accuracy close to $100 \%$ for the training areas and about $80 \%$ for the test areas. 


\section{CONCLUSIONS}

An analysis has been performed of the classification potential for crop classification applications of polarimetric, dual-frequency, multitemporal SAR data. The improvement of using the full polarimetric information compared to combinations of the linear polarizations is largest at L-band, due to the larger sensitivity of for instance the phase difference to the vegetation structure at L-band. Therefore, the best results for single frequency combinations are obtained for $\mathrm{L}$ band. On the other hand, the most stable results using the test areas are obtained using $\mathrm{C}$-band, due to the smaller variability at $\mathrm{C}$-band. Both dual-frequency and multitemporal combinations produce large improvements over single frequency, single data acquisitions. It is foreseen that it will be possible to further improve the results by including information about the incidence angle in the classification and by further speckle reduction using advanced speckle filters.

\section{REFERENCES}

[1] Ulaby, F. T., R. K. Moore, and A. K. Fung, 1986, Microwave Remote Sensing: Active and Passive, vol. III, Dedham, MA: Artech House.

[2] Schotten, C. G. J., W. W. L. van Rooy, and L. L. F. Janssen, 1995, "Assessment of the capabilities of multi-temporal ERS-1 SAR data to discriminate between agricultural crops", Int. J. Rem. Sens., vol. 16, pp. 2619-2637.
[3] Basili, P., P. Ciotti, G. D'Auria, F. S. Marzano, N. Pierdieca, and P. Quarto, 1994, "Assessment of polarimetric features to discriminate land cover from the MAESTRO 1 campaign", Int. J. Remote Sensing, vol 15, pp. 2887-2899.

[4] Freeman, J. Villasenor, J. D. Klein, P. Hooegeboom, and J. Groot, 1994, "On the use of multi-frequency and polarimetric radar backscatter features for classification of agricultural crops", Int. $J$. Remote Sensing, vol 15, pp. 1799-1812.

[5] Lemoine, G. G., G. F. de Grandi, and A. J. Sieber, 1994, "Polarimetric contrast classification of agricultural fields using MAESTRO I AIRSAR data", Int. J. Remote Sensing, vol 15, pp. 2851-2869.

[6] Foody, G. M., M. B. McCulloch, and W. B. Yates, "Crop classification from C-band polarimetric radar data", Int. J. Remote Sensing, vol 15, pp. 2871-2885.

[7] Davidson, M. W. J., R. Steingiesser, and W. Kuhbauch, 1996, "Assessing Agricultural Land Use Early During the Growing Season Using Multi-Frequency and Multi-Polarisation SIR-C Backscatter Features", Proc. EUSAR'96, Königswinter, Germany, pp. 473-476.

[8] Christensen, E L., N. Skou, J Dall, K. Woelders, A. Netterstrom, J.H. Jorgensen, J. Granholm, and S.N. Madsen, 1998, "EMISAR: Polarimetric L- and C-band SAR", IEEE Trans. Geosci. Remote Sens., vol. 36, pp. 1852-1865.

[9] Skriver, H., M.T. Svendsen, and A. Thomsen, 1997, "Crop Monitoring by the dualfrequency, polarimetric EMISAR", Proc. Third Int. Airborne Rem. Sens. Conf. and Exh.,pp. II-753 - II-760.

[10] Lee, J.S., and M.R. Grunes, 1994, "Classification of multi-look polarimetric SAR imagery based on complex Wishart distribution", Int. J. Rem. Sens., vol. 15, pp. 2299-2311.

[11] Skriver, H., M. T. Svendsen, and A. Thomsen, 1999, "Multi-Temporal C- and L-band Polarimetric Signatures Crops", accepted for publication in IEEE Transactions on Geoscience and Remote Sensing.

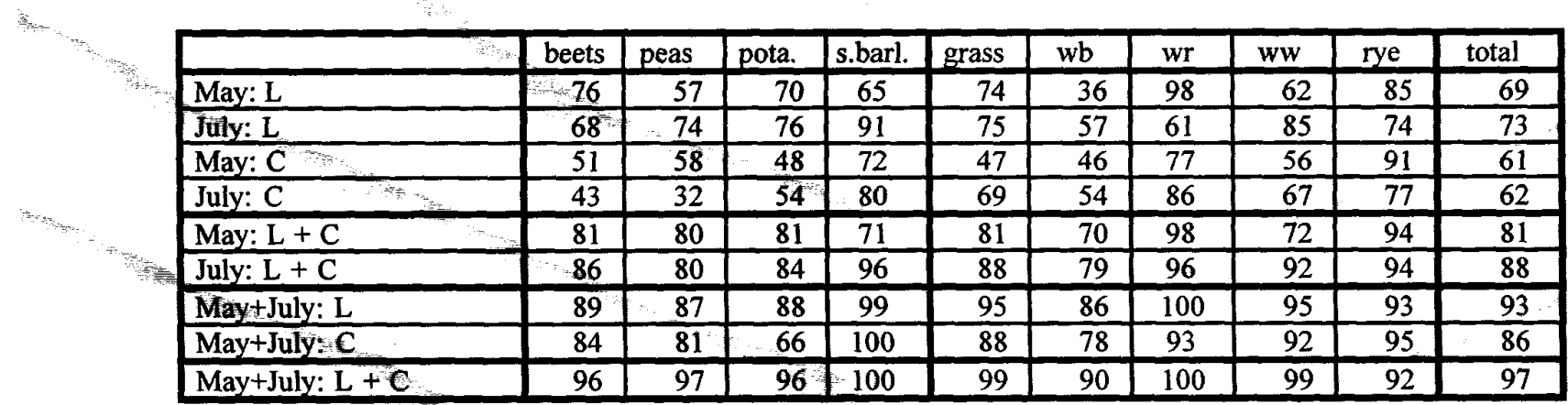

Table 1. Classification accuracies in percent for the various frequency and date combinations, and shown for the individual crops together with the total classification accuracy for the training areas.

\begin{tabular}{|l|r|r|r|r|r|r|r|r|r|r|}
\hline & beets & peas & pota. & s.barl. & grass & wb & wr & ww & rye & total \\
\hline May: L & 47 & 50 & - & 8 & 48 & 16 & 90 & 49 & 35 & 43 \\
\hline July: L & 62 & 43 & - & 69 & 58 & 29 & 31 & 62 & 38 & 49 \\
\hline May: C & 39 & 47 & - & 31 & 33 & 17 & 58 & 41 & 44 & 39 \\
\hline July: C & 53 & 26 & - & 41 & 61 & 26 & 77 & 53 & 70 & 51 \\
\hline May: L + C & 58 & 56 & - & 7 & 55 & 31 & 92 & 55 & 52 & 51 \\
\hline July: L + C & 82 & 63 & - & 58 & 76 & 32 & 86 & 73 & 58 & 66 \\
\hline May+July: L & 65 & 55 & - & 74 & 79 & 44 & 92 & 74 & 45 & 66 \\
\hline May+July: C & 78 & 76 & - & 70 & 73 & 37 & 80 & 77 & 62 & 69 \\
\hline May+July: L + C & 78 & 73 & - & 86 & 88 & 56 & 96 & 88 & 62 & 78 \\
\hline
\end{tabular}

Table 2. Classification accuracies in percent for the various frequency and date combinations, and shown for the individual crops together with the total classification accuracy for the test areas (no test areas for potatoes). 